\title{
EMBEDDED ENGINEERING FOR LOW NOISE GEAR PUMPS
}

\section{OPRAN, C.; PRICOP, M. \& TEODORU, C.}

Abstract: This work presents the results of the researches with application in production to achieve innovative low-noise gear pumps using the embedded engineering. It presents the research findings on the pump operating parameters in order to reduce by $70 \%$ the pressure pulsations resulting low frequency noise of gear pumps. Innovative design feature is given by the use of gears with inclined teeth at $15^{\circ}-20^{\circ}$ with small play of gears and integration of innovative clearing pieces. The embedded engineering of the low-noise pumps leads to a progressive - continuous pumping system resulting a minimum pulsation of the discharge pressure. The research results lead to increased market competitiveness of the pumps made, which have a noise level of $55 \mathrm{~dB}$ at pressures up to 250 bar and $1000 \ldots . .4000$ $\mathrm{rev} / \mathrm{min}$, depending on the geometric volume, in the same time accompanying with a very low pulsation of the pressure.

Key words: silent mesh, gear, pump, noise
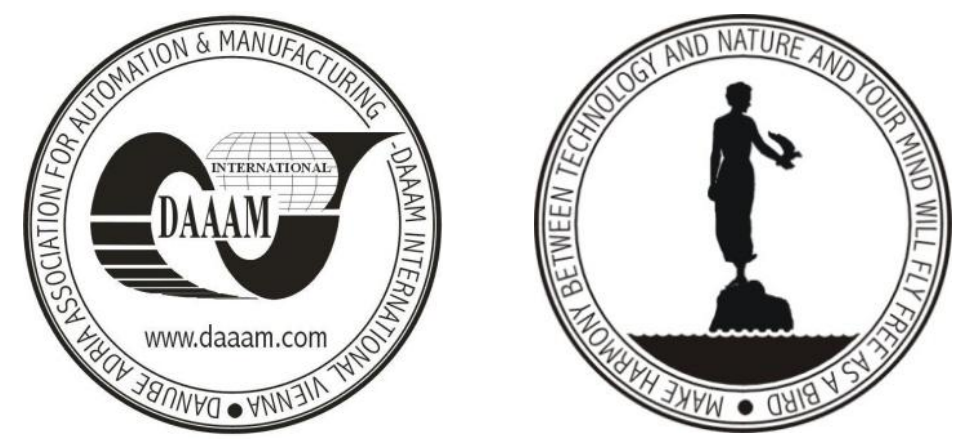

Authors' data: Prof.univ.PhD.MSc.Ing. Opran, C[onstantin]*; PhD.Ing. Pricop, $\mathrm{M}$ [ircea]**; Ing. Teodoru, C[onstantin]**; *University POLITEHNICA of Bucharest, 313 Splaiul Independentei, Bucharest, Romania; ** SC HESPER SA, 1 Dr.Istrati Constantin, 040542 Bucharest, Romania; constantin.opran@ltpc.pub.ro, cornellazar@hesper.ro, hesper@hesper.ro.

This Publication has to be referred as: Opran, C[onstantin] G[heorghe]; Pricop, M[ircea] \& Teodoru, C[onstantin] (2014). Embedded Engineering for Low Noise Gear Pumps, Chapter 13 in DAAAM International Scientific Book 2014, pp.163-170, B. Katalinic (Ed.), Published by DAAAM International, ISBN 978-3-901509-98-8, ISSN 1726-9687, Vienna, Austria

DOI: $10.2507 /$ daaam.scibook.2014.13 
Opran, C. G.; Pricop, M. \& Teodoru, C.: Embedded Engineering for Low Noise Ge...

\section{Introduction}

The standard hydraulic gear pumps are made with right teeth with involute profile and, even if assure high functional parameters, generate noise because of the gearing and also rather higher hydraulic pulsations (Chira et. al., 2009).

The market requests pumps with same functional parameters, but with a reduced noise level and who does not generate hydraulic pulsations and vibrations in the hydraulic installations without accumulator (Opran et. al.,2014), (Ebner et. al., 2011), (Johannes, 2009).

In present there are many international manufactures of gear pumps who aim to develop products in order to achieve high performance operating parameters in terms of noise level and efficiency.

The main directions concerning the low noise gear pumps researches are focused on the following constructive variants (Chira et. al., 2009):

a) Pumps with right teeth - involute profile and very small clearance in the teeth.

This construction assures a reduction of the hydraulic pulsation with approximately 60\%; the sealing between the teeth is made in 3 points according with fig. 1 (Egbe, 2013).

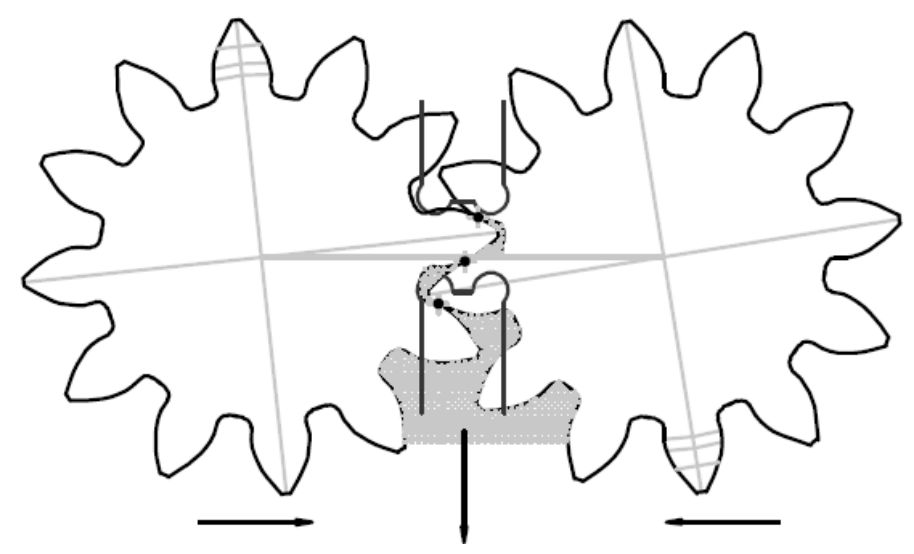

Fig. 1. The gearing in pumps with very small clearance in right teeth

These pumps must fulfill strictly technological constructive conditions regarding the distance between the gearing axis, the teeth run-out and profile and the discharge channel position of the crushed liquid.

b) Pumps with inclined teeth - involute profile.

For these gear pumps the noise produced by gearing is reduced due to increased coverage provided by the inclined teeth and the continuous pumping, which reduces hydraulic pulsations by about $70 \%$.

These pumps are not requiring crushed liquid discharge channel on compensators surfaces which are in contact with the front surface of the pinions teeth.

In terms of technology, these pumps are difficult to be realized due to very strict conditions imposed for the distance between the gearing axis, the teeth run-out and profile. 
c) Pumps with inclined teeth - rounded profiles, with small numbers of teeth and large inclination angle.

These pumps provide extremely quiet operation even at high speeds and very low flow pulsation.

Like previous type of teeth, the rounded teeth are difficult to be manufactured due to very strict conditions imposed for the key parameters mentioned above.

Due to the inclination angle of the teeth, the necessary force of hydraulic compensation of the axial clearances is higher than for the usual pumps (to retrieve the supplementary axial forces from gearing).

Based on the teeth performances presented in the analysis above, our research focuses on the last technical solution, rounded teeth.

\section{Construction of gear pumps with inclined teeth}

The construction of pumps with rounded teeth is shown in Fig. 2. These pumps consist of a pair of pinions, pos.1 (driving pinion) and pos. 2 (driven pinion), which are bearing in two compensators pos. $3 \mathrm{a}$ and $3 \mathrm{~b}$. This package of pinions compensators is mounted in the body, pos. 6 and is axially limited to the fastening flange, pos. 5, and to the cover, pos. 7, having seals, pos. 8 and pos. 9.

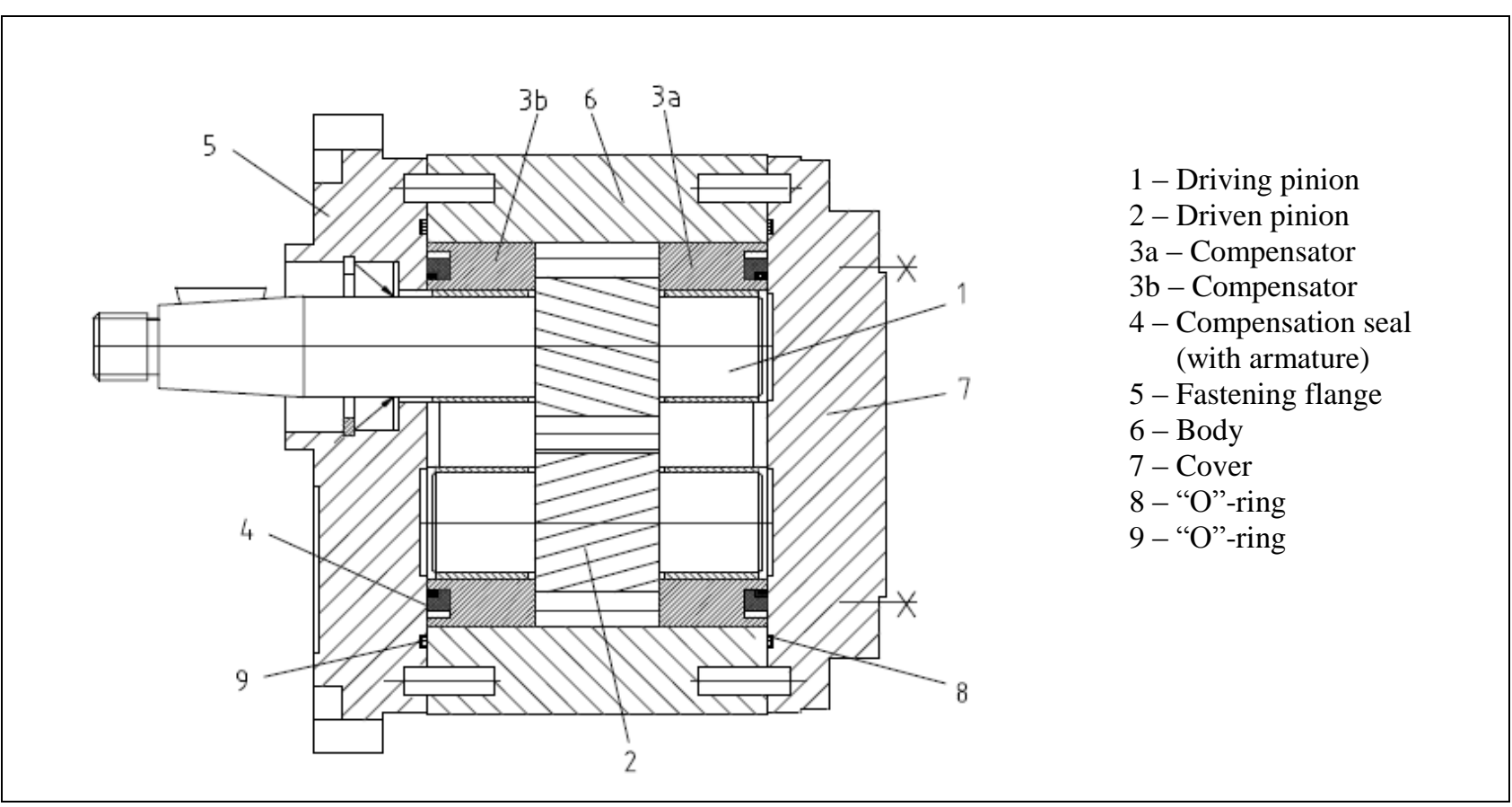

Fig. 2. Construction of gear pumps with rounded teeth

The optimization of the axial clearances is done by the compensators pos. $3 \mathrm{a}$ and $3 \mathrm{~b}$, along with compensation seals, pos. 4. ( Casoli et. al., 2005). The compensators are hydraulically pushed to the pinions with a force bigger than the hydraulic force of compensators rejection to the pinions. In this way, the compensators always remain in contact with the pinions, no matter the pressure and working speed. 
Opran, C. G.; Pricop, M. \& Teodoru, C.: Embedded Engineering for Low Noise Ge...

The pump body, pos.6, together with the pinions and the compensators, delineates two areas, one of high pressure, where the teeth enters in gearing, and one of low pressure, where the teeth are out of gearing, as in fig. 3 .

At the teeth exit from gearing, the gaps between the teeth are filled with the pumped fluid, and at the teeth entering in gearing, fluid is evacuated.

The circulation of the liquid is ensured through the outside of the pinions as in fig. 3 .

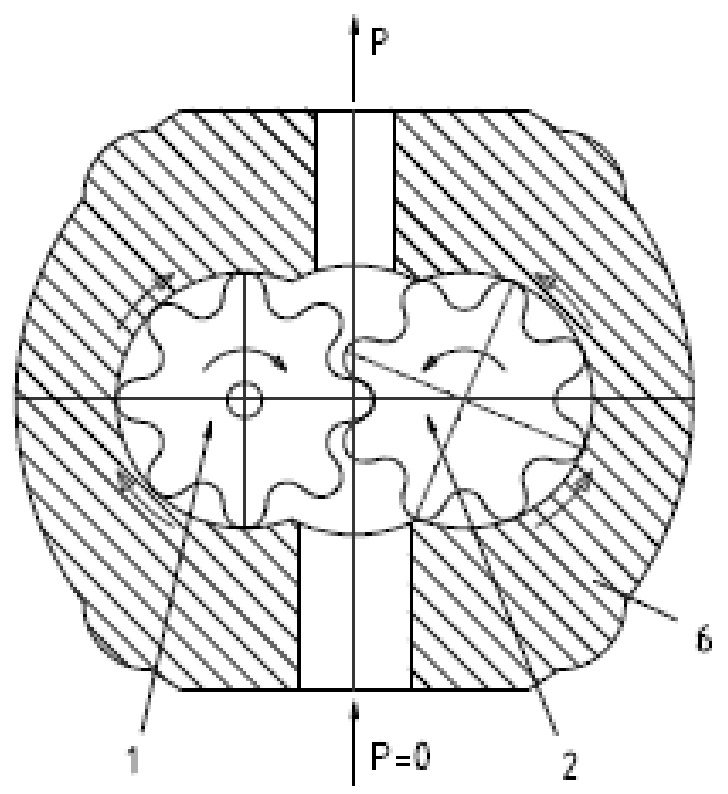

Fig. 3. The circulation of the liquid inside the gear pumps

To avoid the crushed fluid entrapment between the teeth and for drastic reduction of pumps noise was used inclined teeth. The type of teeth is special when the teeth profile is made of circular arcs and line segments, which allows a continuous pumping and a good sealing on the teeth bottom.

The gearing is working with very small and relatively constant clearances at teeth bottom and on the tooth flanks. For this reason it allows high volumetric efficiencies at pressures up to 250 bars, simultaneously with an extremely low noise at speeds between $300 . . .4000 \mathrm{rev} / \mathrm{min}$.

Another characteristic of this gearing is that does not require any clearance to evacuate the crushed fluid, because it does not exist; but the form of compensators is much simplified. These are major advantages in the manufacturing of pumps (allow the standardization of the low noise pumps).

Due to the inclination of teeth, on one of the pinions face a sharp edge is formed in the direction of rotation which tends to wear the compensator (marked with "h"); at the other end the sharp edge is not in the direction of rotation (marked with "g") and therefore cannot cause wear. For this reason, the pumps have two types of compensators (fig. 4): one with lubrication prints at the end with sharp edges in the direction of rotation, pos. 3a, and one without prints on the other end, pos. $3 \mathrm{~b}$. The lubrication prints are designed to permanently maintain a film of oil between pinions and compensator to prevent direct contact and compensators wear. 
The continuous pumping accomplished with inclined teeth is represented in fig. 5 (are presented successively more views of gearing in the front plane). It can be seen that the liquid is sucked and discharged continuously. At each level there is a sealing area between the discharge and suction.

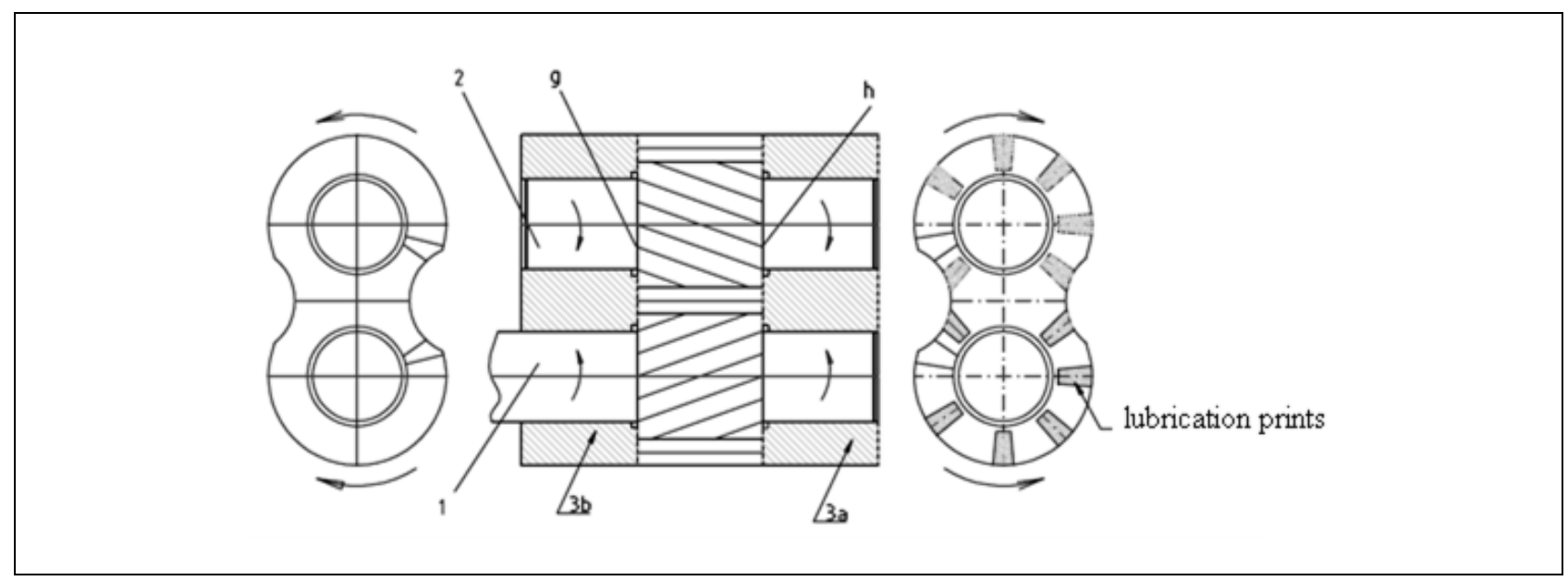

Fig. 4. Compensators with and without lubrication prints

Extremely small clearance at the bottom and the special teeth profile reduce greatly the volume loss of fluid, leading to a high volumetric efficiency.

It can be observed that no closed cavities are formed to capture crushed liquid. Discharge and suction cavities are always open and allow a continuous flow of fluid, without flow or pressure pulsations.
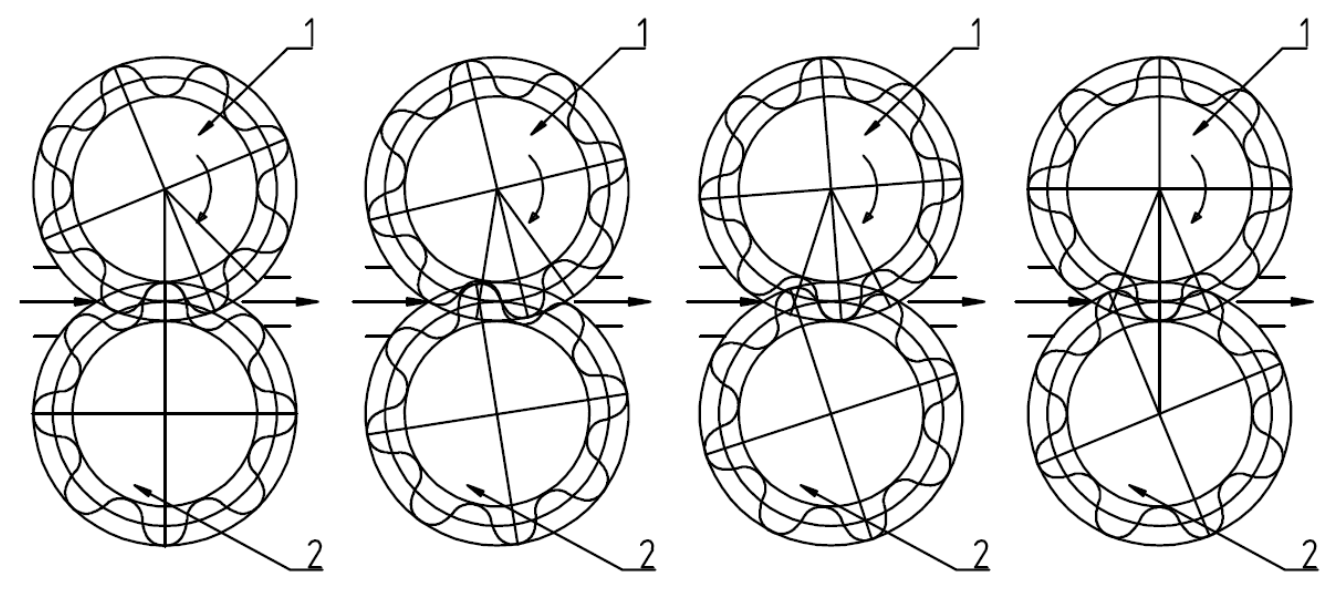

Fig. 5. Continuous pumping

\section{Generating the rounded teeth from normal rack reference}

Normal reference rack is determined by normal pitch $P_{n}$, radius $R_{1}$ from bottom of the tool, the tool top radius $R_{2}$ and teeth height $H$.

The front rack that generates the gear wheel is built by points, based on the following calculation relations (1-3): 
Opran, C. G.; Pricop, M. \& Teodoru, C.: Embedded Engineering for Low Noise Ge...

$$
\begin{aligned}
& P_{f}=\frac{P_{n}}{\cos \beta} \\
& X_{f i}=\frac{X_{n i}}{\cos \beta} \\
& Y_{f i}=Y_{n i}
\end{aligned}
$$

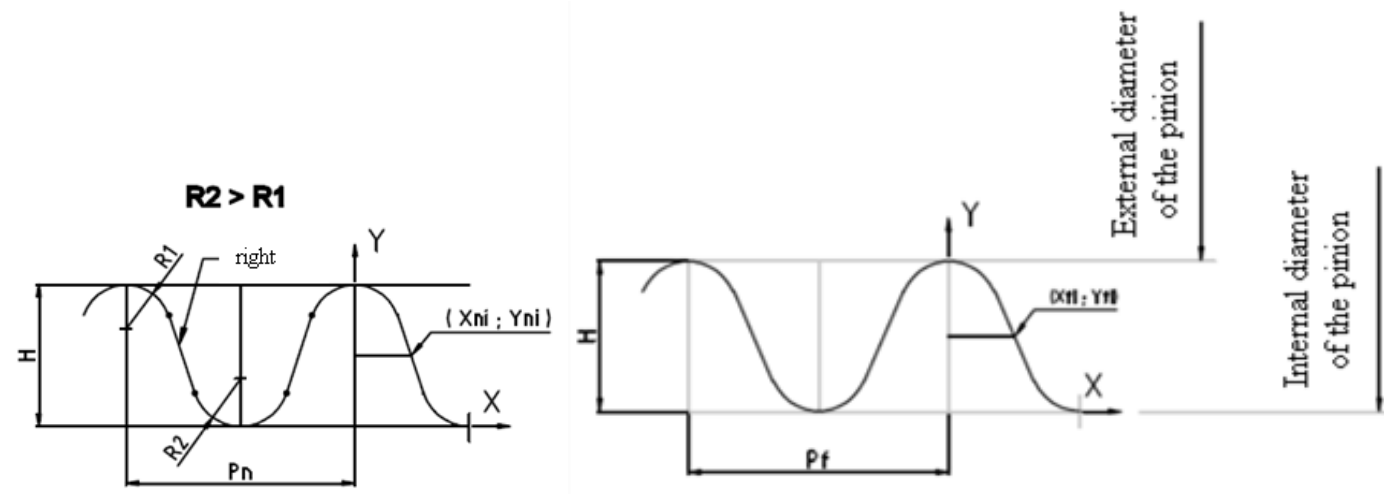

Fig. 6. The transition from normal reference rack, at the front one (a) Normal reference rack; (b) Front reference rack

The teeth in the front plane can be generated graphically by running the front rack over the gear wheel, or by rack rolling on a tooth.

The two generation modes are shown schematically in fig. 7.

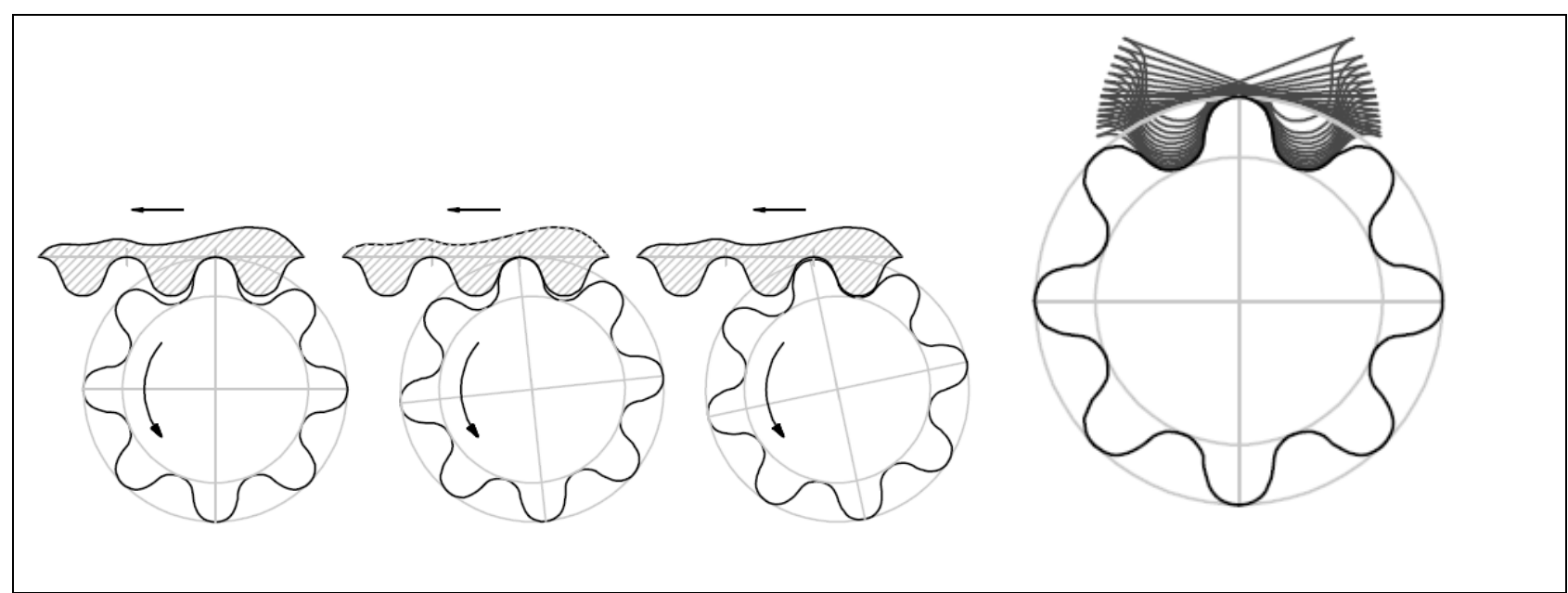

Fig. 7. Ways to generate front teeth of gears (a) Generating by rolling; (b) Generating by the rack rolling on the tooth

\section{Experimental results obtained with low noise pumps with rounded teeth}

In order to validate the rounded teeth performances concerning noise level, several tests were made on stands equipped with advanced equipment taking into consideration the standard pumps displacements (between $2 \ldots 6 \mathrm{~cm}^{3} / \mathrm{rev}$ ), nominal pressures, maximal pressures and speeds between $1000 \ldots 4000 \mathrm{rev} / \mathrm{min}$. The obtained values are summarized in table 1 . 


\begin{tabular}{|c|c|c|c|c|c|c|}
\hline \multirow{2}{*}{$\begin{array}{c}\mathrm{Vg} \\
{\left[\mathrm{cm}^{3} / \mathrm{rev}\right]}\end{array}$} & \multicolumn{5}{|c|}{ at $1000 \ldots 4000 \mathrm{rev} / \mathrm{min}$} & \multirow{2}{*}{$\begin{array}{c}\max . \text { noise } \\
{[\mathrm{dB}]}\end{array}$} \\
\hline & $\begin{array}{c}\text { Pn } \\
{[\mathrm{bar}]}\end{array}$ & $\begin{array}{c}\text { Pmax } \\
{[\text { bar] }}\end{array}$ & $\begin{array}{c}\eta \mathrm{V} \\
{[\%]}\end{array}$ & $\begin{array}{c}\eta t \\
{[\%]}\end{array}$ & $\begin{array}{c}\eta \mathrm{m} \\
{[\%]}\end{array}$ & \\
\hline 2 & \multirow{6}{*}{250} & \multirow{6}{*}{280} & 89 & 76 & 68 & \multirow{8}{*}{54} \\
\hline 2,2 & & & 90 & 78 & 70 & \\
\hline 2,6 & & & 91 & 80 & 73 & \\
\hline 3,2 & & & 92 & 82 & 75 & \\
\hline 3,8 & & & 94 & 84 & 79 & \\
\hline 4,3 & & & 95 & 85 & 81 & \\
\hline 5 & 235 & 260 & 96 & 85 & 82 & \\
\hline 6 & 190 & 210 & 97 & 85 & 83 & \\
\hline
\end{tabular}

Tab. 1. Operating parameters of low noise pumps

Tests revealed that the operating parameters were similar with the parameters of the standards pumps but the noise level did not exceed $54 \mathrm{~dB}$ (at $1000 \mathrm{rev} / \mathrm{min}$.... $4000 \mathrm{rev} / \mathrm{min}$ ) and $55 \mathrm{~dB}$ for extreme tests. These pumps provide extremely quiet operation even at high speeds and very low flow pulsation; pumping is continuous, without requiring discharge channel of crushed liquid.

Furthermore the pumps achieve pressures of $2 \ldots .4$ bars in the compressor mode (air pumping), condition very important for pumps priming which have a check valve on the outlet side (at mini power packs).

The pumps realized with this type of teeth have very high volumetric efficiency, even at relatively high pressures (250 bars).

After testing a large sample of pumps was found that low noise pumps work also as hydraulic motors with opposite direction (Stazhkov, 2013).

Based on the good results obtained by theoretical researches and stand tests we can summarize the advantages of using the teeth with the reference profile consisting of circular arcs and line segments in pumps construction, as follows:

- the gearing is continuous, with contact on the entire length of the tooth;

- very small clearances can be made at the bottom of the teeth that allow high volumetric efficiencies at high pressure;

- flow and pressure pulsations are significantly reduced (by about 80\% smaller than at the standard pumps);

- very low noise level at speeds between $300 . . .4000 \mathrm{rev} / \mathrm{min}$;

- it can be manufactured pumps with different displacements using pinions with the same inclination of the teeth;

- through a judicious design, can be made low noise pumps in the same overall dimensions as standard pumps, and the pinions number of teeth will be obtained from constructive reasons.

\section{Conclusion}

The problem was that standard hydraulic gear pumps with straight teeth generate noise because of the gearing and hydraulic pulsations. This is solved by the special teeth proposed by authors that provide extremely quiet operation even at high speeds 
Opran, C. G.; Pricop, M. \& Teodoru, C.: Embedded Engineering for Low Noise Ge...

and very low flow pulsation and allow manufacturing of low noise pumps with the same overall dimensions as the standard pumps. The result of research lead to increased market competitiveness of the pumps which have a noise level of $54 \mathrm{~dB}$ at pressures up to $250 \mathrm{bar}$ and $1000 \ldots . .4000 \mathrm{rev} / \mathrm{min}$, depending on the geometric volume, in the same time accompanying with a very low pulsation of the pressure.

Is solved that different displacements can be made within the family of pumps using the same inclination of the teeth and implicitly the same cutting tool for more displacements.

The future plans consists of extensive and elaborated scientific and technical researches for develop high quality pumps which will improve the work environment, will have high performances in terms of noise level, volumetric efficiency, mechanical efficiency, compact and reliable construction obtained with minimal production time and costs (Jadlovska et. al., 2012).

\section{References}

Casoli, A. \& Franzoni, G. (2005). A numerical model for the simulation of external gear pumps; Proceedings of the JPFS International Symposium on Fluid power, TSUKUBA 2005, 7-10 November 2005; pp. 705- 710

Chira, F., Banica, M.\& LOBONTIU, M. , (2009), Optimising involutes asymmetrical teeth gears software, Daaam International Scientific Book, pp. 363-376, chapter 38, ISBN 978-3-901509-69-8, ISSN 1726-9687, Vienna, Austria

Ebner, D., King, T., Scheller, C.\& Willimschi, E. (2011). Zahnradpumpen; Verlag Moderne industrie (Gear pumps; Modern publishing industry), Sueddeutscher Verlag onpact GmbH, 81677 Munchen, Germania

Egbe, E., (May 2013). Design Analysis and testing, International Journal of Engineering And Science, Vol.3, Issue 2, PP 01-07, Issn(e): 2278-4721, Issn(p):23196483

Jadlovska, A.; Katalinic, B.; Hrubina, K.; Macurova, A. \& Wessely, E. (2012), Solution to the problem control of a distributed parameter process, Daaam International Scientific Book, ISBN 978-3-901509-86-5, ISSN 1726-9687, pp. 169186, chapter 15, Vienna, Austria

Johannes Looman (2009). Zahnradgetriebe Grundlagen, Konstruktionen, Anwendungen in Fahrzeugen (Gear transmission principles, structures, applications in vehicles); Springer-Verlag Berlin

Opran, C. G., Pricop\&M., Teodoru, C., (2014), Research regarding Adaptive Design of gear Pumps Used for Polymetic Products Engineering, International Conference of Technology for polymeric and Composites Products - POLCOM 2014, Bucharest

Stazhkov, S. (2013), Development of an axial-piston hydraulic machine of a drive system, DAAAM International Scientific Book, pp. 277-296, B. Katalinic \& Z. Tekic (Eds.), ISBN 978-3-901509-94-0, ISSN 1726-9687, Vienna, Austria 